\title{
Towards the Strongest Neutral Organic Superbases Based on Intramolecular H-bonds ${ }^{\dagger}$
}

\author{
Danijela Barić and Borislav Kovačević* \\ Quantum Organic Chemistry Group, Division of Organic Chemistry and Biochemistry, \\ Ruđer Bošković Institute, Bijenička 54, 10000 Zagreb, Croatia
}

RECEIVED JUNE 6, 2014; REVISED OCTOBER 7, 2014; ACCEPTED OCTOBER 13, 2014

\begin{abstract}
Utilizing several different trialkylarsine oxides and substituted pyridine N-oxides as a hydrogen bond acceptors in tri-substituted guanidines we designed several very basic superbases possessing intramolecular hydrogen bonds (IHB-superbases), with proton affinity in the gas phase that comes very close to that of paradigmatic $\mathrm{P} 4-\mathrm{Bu}$ Schwesinger superbase and with $\mathrm{p} K_{\mathrm{a}}$ in acetonitrile up to 36 units.
\end{abstract}

Keywords: organic superbases, intramolecular hydrogen bonds, DFT calculations

\section{INTRODUCTION}

Neutral organic bases are important class of compounds in organic synthesis. Large amount of chemical reactions require deprotonation of starting compound as an initial process that activates reactants and enable chemical reaction to proceed. Various types of organic bases of different strength have been developed during the time, trying to achieve higher basicity sometimes needed to abstract the proton from a weak Brønsted acids. The most famous are Schwesinger vinamidines ${ }^{1}$ and phosphazenes, $^{2}$ and Verkade proazaphosphatranes ${ }^{3}$ (Scheme 1). Several other types of molecular skeletons have been developed to achieve high basicity like pro-

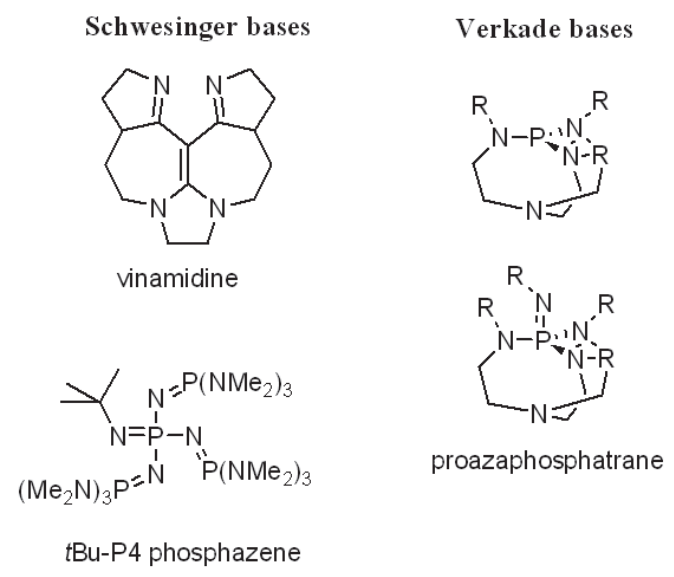

ton sponges, or even some supramolecular cages (I, Scheme 1). ${ }^{4}$ Advances in the field of design and synthesis of organic bases have been summarized lately in two review articles. ${ }^{5,6}$ One particular molecular motif that leads to a highly basic organic compounds is susbtitution of guanidines and/or amines with substituents capable of forming intramolecular hydrogen bonds. Using this molecular motif Bachrach studied several very basic amines, with adamantane compound (II, Scheme 1) being the most basic one. ${ }^{7}$ More than 10 years ago we designed a substituted guanidine superbase (III, Scheme 1) where the basicity of central guanidine core - due to a presence of three intramolecular hydrogen bonds in conjugate acid - was

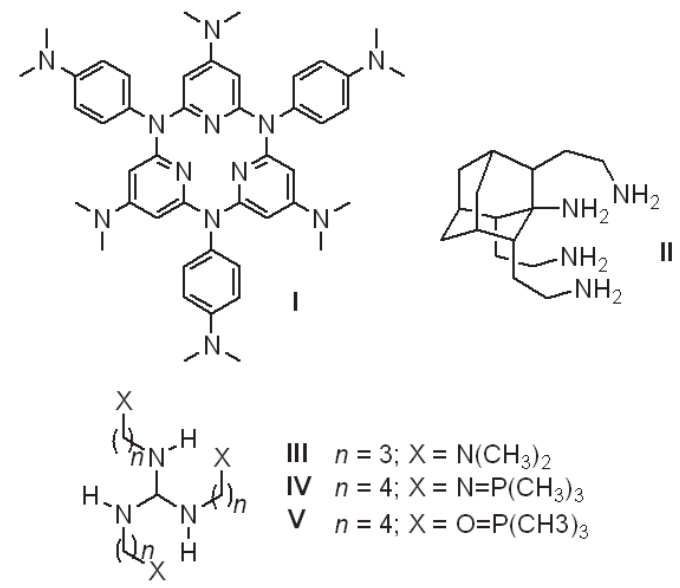

Scheme 1. Representative examples of some superbases.

\footnotetext{
$\dagger$ Dedicated to Dr. Mirjana Eckert-Maksić on the occasion of her $70^{\text {th }}$ birthday.
}

* Author to whom correspondence should be addressed. (E-mail: boris@irb.hr) 
increased by $\approx 25 \mathrm{kcal} \mathrm{mol}^{-1}$ compared to $N, N^{\prime}, N^{\prime \prime}$ trimethylguanidine. ${ }^{8}$ Three years later this compound was synthesized and experimental measurements confirmed the proposed structure and basicity. ${ }^{9}$ Subsequently, some modifications of the original idea have been utilized to obtain more or less basic compounds. Glasovac synthesized compounds with methoxy ${ }^{10}$ and pyridino $^{11}$ group at the end of alkyl chain. Recently, utilizing the same motif combined with use of a very strong H-bond acceptors at the end alkyl chain, we designed a series of very strong neutral organic superbases ("IHB-superbases") with a gas phase proton affinity (PA) up to $293.3 \mathrm{kcal} \mathrm{mol}^{-1}$ and $\mathrm{p} K_{\mathrm{a}}$ in acetonitrile up to 33.2 (IV, V, Scheme 1). ${ }^{12}$ To the best of our knowledge, these are the most basic guanidines designed so far. However, this brings up the question: did we reach the limit of basicity of the substituted guanidines with these compounds? Is it possible to find a stronger H-bond acceptor that would enable design of even stronger guanidines than those designed so far? In this paper we will show that it is feasible to find molecular moieties that can form a H-bonds stronger than alkyl phosphazenes - the strongest $\mathrm{H}$-bond acceptors utilized in our previous study.

\section{COMPUTATIONAL DETAILS}

Calculations in the gas phase were carried out at B3LYP/6-311+G(2df,p)//B3LYP/6-31G(d) level of theory. The vibrational analysis was performed to confirm the energy minima on potential energy surface for all structures.

Proton affinities are calculated according to the Equation:

$$
\mathrm{PA}=H^{298}(\mathrm{~B})-H^{298}\left(\mathrm{BH}^{+}\right)+\frac{5}{2} R T
$$

where $H^{298}(\mathrm{~B})$ and $H^{298}\left(\mathrm{BH}^{+}\right)$represent the enthalpies at $298 \mathrm{~K}$ of the neutral (B) and protonated $\left(\mathrm{BH}^{+}\right)$base, calculated at B3LYP/6-311+G(2df,p)//B3LYP/6-31G(d) level of theory. The $\mathrm{p} K_{\mathrm{a}}$ values in acetonitrile $(\mathrm{MeCN})$ are estimated using a correlation between the experimental data for $\mathrm{p} K_{\mathrm{a}}$ values in $\mathrm{MeCN}$ and calculated basicities: ${ }^{13}$

$$
\mathrm{p} K_{\mathrm{a}}=0.545 \Delta G_{\mathrm{a}, \mathrm{sol}}^{\prime}\left(\mathrm{BH}^{+}\right)-133.5
$$

where $\Delta G_{\mathrm{a}, \mathrm{sol}}^{\prime}\left(\mathrm{BH}^{+}\right)$represents the difference of Gibbs energies between product and reactants for the reaction of deprotonation of $\mathrm{BH}^{+}$in acetonitrile. The Gibbs energy is sum of total electronic energy, the thermal correction to Gibbs energy and the energy of solvation. The solvation energies are calculated using isodensity polarizable continuum (IPCM) method at B3LYP/6-311+ $\mathrm{G}(\mathrm{d}, \mathrm{p}) / / \mathrm{B} 3 \mathrm{LYP} / 6-31 \mathrm{G}(\mathrm{d})$ level of theory.

All computations were performed by the Gaussian $03^{14}$ program package.

\section{RESULTS AND DISCUSSION}

As mentioned in introductory remarks, the strongest IHBsuperbases obtained so far were designed utilizing alkylphosphazene, tris(dimethylamino)phosphine oxide, and trimethylphosphine oxide as an H-bond acceptor at the end of alkyl chain. ${ }^{12}$ According to the experimentally determined $\mathrm{p} K_{\mathrm{BH}}$ values, ${ }^{15}$ it can be expected that alkylsubstituted arsine oxide shows even stronger H-bond accepting ability. The $\mathrm{p} K_{\mathrm{BH}}$ value of $\mathrm{Et}_{3} \mathrm{PO}$ is 3.66, whereas $\mathrm{Et}_{3} \mathrm{AsO}$ has a $\mathrm{p} K_{\mathrm{BH}}$ value of 4.89 . In the same compilation of $\mathrm{p} K_{\mathrm{BH}}$ data it was shown that unsubstituted pyridine $\mathrm{N}$-oxide is a very strong hydrogen bond acceptor $\left(\mathrm{p} K_{\mathrm{HB}}=2.70\right)$, almost as strong as $4-N, N$-dimethylaminopyridine $\left(\mathrm{p} K_{\mathrm{BH}}=2.80\right)$. Substitution of pyridine Noxide with strong electron donating group like dimethylamine at para position would probably significantly increase its H-bond acceptor strength, just as in the case of pyridine where the difference in $\mathrm{p} K_{\mathrm{HB}}$ between unsubstituted pyridine $\left(\mathrm{p} K_{\mathrm{HB}}=1.86\right)$ and $4-N, N^{\prime}-$ dimethylaminopyridine $\left(\mathrm{p} K_{\mathrm{HB}}=2.80\right)$ is almost one unit.

Previously designed IHB-superbases IV and $\mathbf{V}$ (Scheme 1) consisted of the guanidine serving as a central motif in a superbase, and appropriate $N, N^{\prime}, N^{\prime \prime}$ substituents capable to make intramolecular hydrogen bond. To select proper substituents for IHB-superbases designed in this work, we calculated the energy of intermolecular hydrogen bond(s) in complexes built from protonated $N, N^{\prime}, N^{\prime \prime}$-trimethylguanidine and model molecules that possess the ability to form a strong $\mathrm{H}$ bond. Our previous study ${ }^{12}$ showed that the stabilization energy due to the presence of intermolecular H-bond(s) in complexes gave good prediction of basicity that could be obtained in the designed IHB-superbases. Investigated model molecules in this work were alkyl substituted

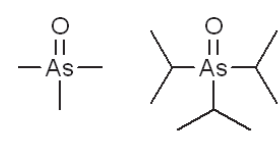

M1

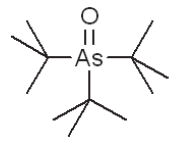

M3

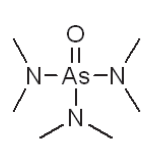

M4
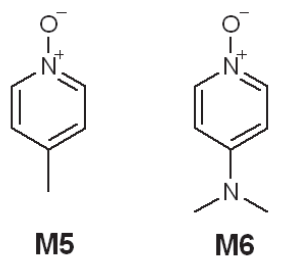

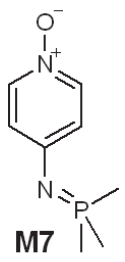

Figure 1. Model molecules used in complexes for estimation of the H-bond strength. 
and dimethylamino substituted arsine oxides (M1-M4, Figure 1) since it is expected that they have stronger $\mathrm{H}$ bond acceptor properties when compared to the corresponding phosphine oxides. ${ }^{15}$ Second group of model molecules were pyridine-N-oxides substituted with strong electron donating groups (M5-M7, Figure 1).

Firstly, the energy for monocomplexes $\left(\Delta H^{298}\right.$ (mono- $)$ are calculated to compare the H-bond acceptor ability of new molecules with previously obtained ones. H-bond enthalpies for monocomplexes are calculated according to the Equation (3).

$$
\begin{gathered}
\mathbf{T M G H}^{+}+\mathbf{M} \rightarrow[\mathbf{T M G H} \cdots \mathbf{M}]^{+} \\
\Delta H^{298}=H^{298}\left([\mathbf{T M G H} \cdots \mathbf{M}]^{+}\right)- \\
\left.-\left(H^{298}(\mathbf{T M G H})^{+}\right)+H^{298}(\mathbf{M})\right)
\end{gathered}
$$

Obtained values of enthalpies for monocomplexes with pyridine $\mathrm{N}$-oxides are in range of -19

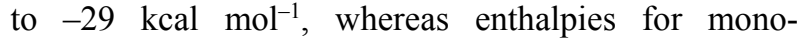
complexes with arsine oxides range between -20 and $-24 \mathrm{kcal} \mathrm{mol}^{-1}$ (Table 1). This implies that the stabilization upon complexation is better when compared with results from our previous study ${ }^{12}$ where the absolute values of enthalpies for mono-complexes did not exceed $23 \mathrm{kcal} \mathrm{mol}^{-1}$. Therefore, it can be expected that some of the IHB-superbases with substituents derived from model molecules M1-M7 would be even more basic than those obtained previously. The conjugate acid of IHB superbases possesses three intramolecular hydrogen bonds that stabilize protonated central guanidine core.$^{8-12}$ It should be noted that according to the classification, this type of hydrogen bonds belongs to the charge assisted hydrogen bonds. ${ }^{16}$

Table 1. The enthalpies of formation of mono-, tri- and dicomplexes, and corrected values of enthalpy of tricomplexations

\begin{tabular}{lcccc}
\hline \multirow{2}{*}{ Molecule } & \multicolumn{4}{c}{$\Delta H^{298} / \mathrm{kcal} \mathrm{mol}^{-1}$} \\
\cline { 2 - 5 } & mono- & tri- & di- & tri-corr \\
\hline M1 & -23.8 & -56.7 & -7.3 & -49.4 \\
M2 & -24.1 & -56.0 & -4.9 & -51.1 \\
M3 & -23.7 & -52.1 & -2.6 & -49.5 \\
M4 & -20.5 & -48.4 & -3.4 & -45.0 \\
M5 & -19.7 & -47.2 & -6.5 & -40.7 \\
M6 & -25.1 & -57.8 & -8.5 & -49.2 \\
M7 & -29.1 & -64.9 & -9.4 & -55.5 \\
\hline
\end{tabular}

To estimate the stabilization energy of three $\mathrm{H}$ bonds on protonated TMG cation, we calculated the stabilization enthalpies of tri-complexes $\left(\Delta H^{298}(\right.$ tri- $\left.)\right)$ according to the Equation (4).

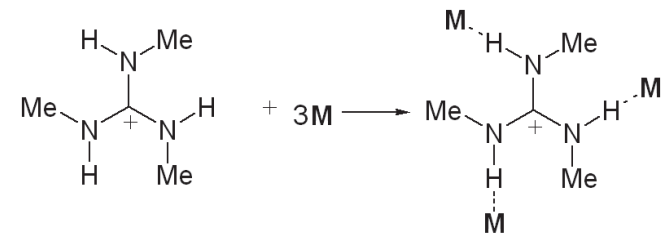

$$
\begin{aligned}
\mathbf{T M G H}^{+}+3 \mathbf{M} \rightarrow\left[\mathbf{T M G H} \cdots \mathbf{M}_{3}\right]^{+} \\
\begin{aligned}
\Delta H^{298} & =H^{298}\left(\left[\mathbf{T M G H} \cdots \mathbf{M}_{3}\right]^{+}\right)- \\
& -\left(H^{298}\left(\mathbf{T M G H}^{+}\right)+3 H^{298}(\mathbf{M})\right)
\end{aligned}
\end{aligned}
$$

Additionally, it should be noted that neutral form of IHB-superbases possess two intramolecular H-bonds between substituents and two hydrogen atoms covalently bonded to nitrogen on central guanidine. Usually, these H-bonds are relatively weak, however, they contribute to the stabilization of neutral form of a molecule. We calculated the stabilization enthalpy, $\Delta H^{298}(\mathrm{di}-)$, between neutral TMG and two molecules $\mathbf{M}$ according to the Equation (5).

$$
\begin{aligned}
\mathbf{T M G} & +2 \mathbf{M} \rightarrow\left[\mathbf{T M G H} \cdots \mathbf{M}_{2}\right] \\
\Delta H^{298} & =H^{298}\left(\left[\mathbf{T M G} \cdots \mathbf{M}_{2}\right]\right)- \\
& -\left(H^{298}(\mathbf{T M G})+2 H^{298}(\mathbf{M})\right)
\end{aligned}
$$

Since the proton affinity is the difference between the energy of neutral and protonated form of the base in question, the increase in PA due to a presence of $\mathrm{H}$-bonds is a result of the difference in H-bond energy in neutral base and H-bond energy in the protonated one. Accordingly, we calculated the 'corrected' H-bond enthalpies $\Delta H^{298}$ (tri-corr) as a difference between $\Delta H^{298}$ (tri-) and $\Delta H^{298}(\mathrm{di}-)$ values. The enthalpies of formation of mono-, tri- and di-complexes, and corrected values of enthalpy of tri-complexations are presented in Table 1. We expect that the PA of newly designed superbases that are built with substituents based on model molecules $\mathbf{M}$ could roughly be the PA of TMG molecule plus the absolute value of $\Delta H^{298}$ (tri-corr). Since the PA of $\mathbf{T} \mathbf{M G}^{12}$ is 249.9 $\mathrm{kcal} \mathrm{mol}^{-1}$, the PA values of new bases could be in range of 290 to $300 \mathrm{kcal} \mathrm{mol}^{-1}$. 
<smiles>[X]CCCCCNC(=NCCCC[X])NCC</smiles><smiles>[Z]C(C)[Si](C(C)C)(C(C)C)C(C)C</smiles><smiles>[X]CCCCCNC(=NCCCC[X])NCCCC[X]</smiles>

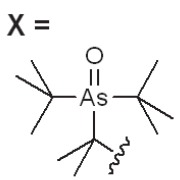

3

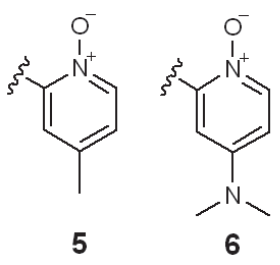

6

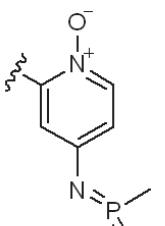

7
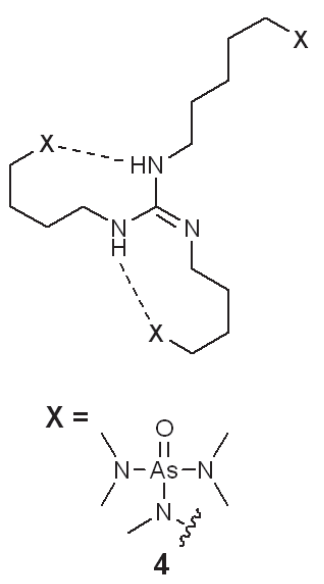

Figure 2. Schematic representation of newly designed IHB-superbases.

Once we selected an appropriate molecules $\mathbf{M}$ that should serve as H-bond accepting substituents, the next phase in designing of IHB-superbases was to find an appropriate alkyl chain that binds central guanidine core and selected substituent based on M. To find a proper chain, we applied the principle of minimal perturbation of arrangement obtained in tri-complexes. The alkyl chain was constructed in such a way to maximally preserve an 'ideal' oriantation of molecules $\mathrm{M}$ around the central guanidine as it was in tricomplexes. The optimal alkyl chain for 1-3 and 5-7 was found to be buthyl, while for base 4 it was pentyl. The newly designed IHBsuperbases are presented in Figure 2.

In molecules 3, 5, $\mathbf{6}$ and $\mathbf{7}$ the oxygen atom on substituents on guanidine forms an intramolecular H-bonds with $\mathrm{H}$ atom attached to the same nitrogen as substituent, thus forming pseudo seven-membered ring. In molecules $\mathbf{1}$ and $\mathbf{2}$ the oxygen atom on substituents forms a hydrogen bond with $\mathrm{H}$ atom attached to a neigboring $\mathrm{N}$ atom, forming an pseudo nine-membered ring. The same pattern is observed in base $\mathbf{4}$, however, due to a longer alkyl chain, the pseudo ten-membered ring is assembled upon formation of intramolecular hydrogen bonds.

Table 2. The calculated gas phase proton affinities (PA) and $\mathrm{p} K_{\mathrm{a}}$ values in acetonitrile for IHB superbases 1-7

\begin{tabular}{lcc}
\hline Superbase & PA / $\mathrm{kcal} \mathrm{mol}^{-1}$ & $\mathrm{p} K_{\mathrm{a}}$ \\
\hline $\mathbf{1}$ & 293.1 & 32.1 \\
$\mathbf{2}$ & 296.9 & 36.7 \\
$\mathbf{3}$ & 296.0 & 32.7 \\
$\mathbf{4}$ & 290.9 & -(a) \\
$\mathbf{5}$ & 289.0 & 29.4 \\
$\mathbf{6}$ & 295.9 & 32.6 \\
$\mathbf{7}$ & 299.4 & -(a) \\
\hline
\end{tabular}

(a) No convergence in the IPCM calculation.
The proton affinities and $\mathrm{p} K_{\mathrm{a}}$ values for bases 1-7 are presented in Table 2. Inspection of data in Table 2 reveals that newly designed IHB-superbases possess gas phase PA between 289 and $299 \mathrm{kcal} \mathrm{mol}^{-1}$, which is by 3 to $6 \mathrm{kcal} \mathrm{mol}^{-1}$ higher than PAs obtained for IHBsuperbases in our previous study. ${ }^{12}$ However, the pKa values are on average not significantly higher. Nonetheless, the superbase 2 with $\mathrm{p} K_{\mathrm{a}}$ of 36.7 is by 3.5 units more basic than superbase $\mathbf{V}$ (Scheme 1) thus representing the most basic IHB-superbase designed so far.

As already mentioned, the effect of intramolecular hydrogen bonds on PA of IHB-superbases can be roughly estimated by calculating the intermolecular H-bonds in complexes between model molecules $\mathbf{M}$ and TMG. However, a more specific analysis performed earlier ${ }^{12}$ showed that intramolecular $\mathrm{H}$-bonds are not the only factor that influences the basicity of IHBsuperbases; the inductive effect of the bridging alkyl chain and the inductive effect of the H-bond accepting substituent at the end of the chain (X, Figure 2) also make significant impact.

We proposed that the total increase in PA $\left(\triangle \mathrm{PA}_{\text {total }}\right)$ for each superbase compared to the corresponding reference molecule TMG may be represented as a sum of three influences: $(i)$ the strength of intramolecular H-bonds $\left(\triangle \mathrm{PA}_{\mathrm{IHB}}\right)$, (ii) the inductive effect of alkyl chain $\left(\triangle \mathrm{PA}_{\text {alkyl }}\right)$, and (iii) the inductive effect of the substituent $\mathbf{X}$ derived from the model molecules $\mathbf{M}$ $(\triangle \mathrm{PAx})$ :

$$
\begin{aligned}
\Delta \mathrm{PA}_{\text {total }} & =\mathrm{PA}(\text { superbase })-\mathrm{PA}(\mathbf{T M G}) \\
& =\Delta \mathrm{PA}_{\mathrm{IHB}}+\Delta \mathrm{PA}_{\text {alkyl }}+\Delta \mathrm{PA}_{\mathbf{X}}
\end{aligned}
$$

Here, $\triangle \mathrm{PA}_{\mathrm{IHB}}$ is obtained as a difference between the PA of superbases in folded conformation when $\mathrm{H}$ bonds are present, and PA of unfolded (zig-zag) con- 
Table 3. Analysis of various contributions to the proton affinities (PA) of IHB-superbases 1-7

\begin{tabular}{|c|c|c|c|c|c|c|}
\hline \multirow{2}{*}{ Superbase } & \multicolumn{6}{|c|}{ Proton affinities / kcal mol ${ }^{-1}$} \\
\hline & PA & $\Delta \mathrm{PA}_{\text {total }}$ & PAunfolded & $\triangle \mathrm{PA}_{\text {Iнв }}$ & $\Delta \mathrm{PA}_{\text {alkyl }}$ & $\Delta \mathrm{PAx}$ \\
\hline 1 & 293.1 & 43.2 & 255.8 & 37.2 & 6.7 & -0.8 \\
\hline 2 & 296.9 & 47.0 & 267.6 & 29.3 & 6.7 & 11.0 \\
\hline 3 & 296.0 & 46.1 & 252.3 & 43.7 & 6.7 & -4.3 \\
\hline 4 & 290.9 & 41.0 & 259.2 & 31.8 & 7.5 & 1.8 \\
\hline 5 & 289.0 & 39.1 & 253.6 & 35.5 & 6.7 & -3.0 \\
\hline 6 & 295.9 & 46.0 & 256.8 & 39.2 & 6.7 & 0.2 \\
\hline 7 & 299.4 & 49.5 & 265.1 & 34.2 & 6.7 & 8.7 \\
\hline
\end{tabular}

formers where intramolecular $\mathrm{H}$-bonds do not exist. The term $\Delta \mathrm{PA}_{\text {alkyl }}$ represents the difference in PAs between trisalkyl-substituted guanidine and the corresponding reference molecule TMG. As stated above, we found that for bases 1-3 and 5-7 the optimal chain was butyl whereas for base $\mathbf{4}$ the optimal chain is pentyl. The proton affinity of $N, N^{\prime}, N^{\prime \prime}$-trisbutylguanidine is $6.7 \mathrm{kcal}$ $\mathrm{mol}^{-1}$ higher than the PA of TMG, whereas the PA of $N, N^{\prime}, N^{\prime \prime}$-trispentylguanidine is increased by $7.5 \mathrm{kcal}$ mol $^{-1}$ compared to TMG.

The last term, $\triangle \mathrm{PAx}$, which represents the contribution to the increase of PA by inductive effect of the $\mathrm{H}$-bond accepting substituent $\mathbf{X}$ at the end of the chain, is calculated as a difference in PAs between the unfolded superbase and molecule of trisbutyl-subtituted guanidine $\left(\mathrm{PA}=256.6 \mathrm{kcal} \mathrm{mol}^{-1}\right)$ or trispentyl-substituted guanidine $\left(\mathrm{PA}=267.4 \mathrm{kcal} \mathrm{mol}^{-1}\right)$. A detailed analysis for superbases 1-7 is presented in Table 3 .

In all IHB-superbases the biggest contribution to the increase of PA are intramolecular H-bonds, represented by term $\triangle \mathrm{PA}_{\mathrm{IHB}}$. The strongest influence of $\mathrm{H}-$ bonds is noticed in $\mathbf{3}$ and $\mathbf{6}$, however, they are not the most basic molecules here. The reason for that lies in the fact that the inductive effect of their substituents $\mathbf{X}$ (tert $\mathrm{Bu}$-arsine-oxide and dimethylamino-piridine $\mathrm{N}$ oxide) are negative (being $-4.3 \mathrm{kcal} \mathrm{mol}^{-1}$ for molecule $3)$ and neutral $\left(0.2 \mathrm{kcal} \mathrm{mol}^{-1}\right.$ for superbase 6). Since the $\triangle \mathrm{PAx}$ represents the contribution to the increase of $\mathrm{PA}$ due to the presence of substituent $\mathbf{X}$ when alkyl chain is unfolded, the negative value of $\triangle \mathrm{PAx}$ means that $\mathbf{X}$ withdraws electrons from the central guanidine and thus diminishes a proton affinity. At the same time, that positively influences the H-bond accepting ability of $\mathbf{X}$, resulting in a relatively strong $\mathrm{H}$-bonds as found in $\mathbf{3}$ and, in less extent, in $\mathbf{6}$.

The most basic is molecule 7 , with phosphazenosubstituted piridine-N-oxide as a substituent $\mathbf{X}$. The positive inductive effect of $\mathbf{X}$ is strong, being almost 9 kcal mol ${ }^{-1}$, which combined with also strong intramolecular H-bonds $\left(\approx 34 \mathrm{kcal} \mathrm{mol}^{-1}\right)$ results in the biggest increase of PA when compared with TMG.

\section{CONCLUSIONS}

Based on the step by step approach in designing of IHBsuperbases with the guanidine as a core fragment and heteroalkyl substituents, we designed seven new molecules that possess the gas phase proton affinity higher than those obtained so far. The substituents are chosen according to their H-bond accepting ability, that was firstly tested by building the complexes between model molecules and $N, N^{\prime}, N^{\prime \prime}$-trimethylguanidine. Alkyl chains bind the substituent with a central core and at the same time they enable optimal arrangement of the atoms which are involved in formation of $\mathrm{H}$-bonds - i.e. the geometry of the complexes should be preserved in a great extent. The values of the PAs for designed IHB-superbases range from 289.0 to $299.4 \mathrm{kcal} \mathrm{mol}^{-1}$, while $\mathrm{p} K_{\mathrm{a}}$ values vary between 29.4 and 36.6 units. IHB-superbases owe their high basicity to the presence of three intramolecular hydrogen bonds in protonated form of the molecule, however, two more additional contributions have an influence to their PA. These contributions are the inductive effect of alkyl chains present in a molecule, and the inductive effect of the substituent $\mathbf{X}$. The inductive effect of alkyl is always positive, but the inductive effect of the $\mathbf{X}$ depends on the character of the $\mathbf{X}$. If $\mathbf{X}$ donates electrons through the alkyl chain toward the central core, then the basicity is additionally increased, as in superbases 2 and 7 . In molecules $\mathbf{3}$ and $\mathbf{5}$, the $\mathbf{X}$ has negative inductive effect behaving as an electron acceptor that withdraws electrons from the central guanidine, thus having negative influence to basicity. On the other side, this electron-accepting behaviour of $\mathbf{X}$ results in a stronger $\mathrm{H}$-bonds, so the final increase of PA is still preserved. For molecules 1, 4 and 6 the inductive effect of $\mathbf{X}$ is negligible and does not influence basicity.

We believe that superbases 1-7 should be synthetically available and we look forward for their preparation and application.

Acknowledgement. Our thanks go to the Computing Center of the University of Zagreb (SRCE) for granting computational time on ISABELLA cluster. 


\section{REFERENCES}

1. (a) R. Schwesinger, Angew. Chem. Int. Ed. Engl. 26 (1987) 1164-1165; (b) R. Schwesinger, M. Missfeldt, K. Peters, and H. G. von Schnering, Angew. Chem. Int. Ed. Engl. 26 (1987) 11651167.

2. (a) R. Schwesinger and H. Schlemper, Angew. Chem. Int. Ed. Engl. 26 (1987) 1167-1169; (b) R. Schwesinger, Nachr. Chem. Tech. Lab. 38 (1990) 1214-1226; (c) R. Schwesinger, J. Willaredt, H. Schlemper, M. Keller, D. Schmitt, and H. Fritz, Chem. Ber. 127 (1994) 2435-2454; (d) R. Schwesinger, H. Schlemper, C. Hasenfratz, J. Willaredt, T. Dambacher, T. Breuer, C. Ottaway, M. Fletschinger, J. Boele, H. Fritz1, D. Putzas, H. W. Rotter, F. G. Bordwell, A. V. Satish, G.-Z. Ji, E.-M. Peters, K.Peters, H. G. von Schnering, and L. Walz, Liebigs Ann (1996) 1055-1081; (e) I. Kaljurand, T. Rodima, I. Leito, I. A. Koppel, R. Schwesinger, J. Org. Chem. 65 (2000) 6202-6208.

3. (a) J. G. Verkade, Acc. Chem. Res. 26 (1993) 483-489; (b) J. G. Verkade, Coord. Chem. Rev. 137 (1994) 233-295; (c) A. E. Wroblewski, J. Pinkas, and J. G. Verkade, Main Group Chem. 1 (1995) 69-79; (d) J. G. Verkade, Phosphorus, Sulfur, Silicon Relat. Elem. 177 (2002)1621-1631; (e) J. G. Verkade, New Aspects Phosphorus Chem. II (Top. Curr. Chem.) 223 (2003) 144; (f) J. G. Verkade, P. B. Kisanga, Aldrichimica Acta 37 (2004) 3-14

4. (a) I. Despotović, B. Kovačević, and Z. B. Maksić, New J. Chem. 31 (2007) 447-457; (b) I. Despotović, B. Kovačević, and Z. B. Maksić, Org. Lett. 9 (2007) 1101-1104 (c) I. Despotović, B Kovačević, and Z. B. Maksić, Org. Lett. 9 (2007) 4709-4712; (d) N. Uchida, J. Kuwabara, A. Taketoshi, and T. Kanbara, J. Org. Chem. 77 (2012) 10631-10637.

5. Z. B. Maksić, B. Kovačević, and R. Vianello, Chem. Rev. 112 (2012) 5240-5270

6. T. Ishikawa and D. Margetić, In: T. Ishikawa (Ed.), Perspectives//Superbases for organic synthesis: guanidines, amidines, phosphaznes and related organocatalysts, Chichester, West Sussex: John Wiley \& Sons, Ltd, (2009), pp 315-320.

7. (a) S. M. Bachrach, Org. Lett. 14 (2012), 5598-5601; (b) S. M. Bachrach, J. Org. Chem. 78 (2013) 10909-10916.

8. B. Kovačević, Z. Glasovac, and Z. B. Maksić, J. Phys. Org. Chem. 15 (2002) 765-774.

9. Z. Glasovac, B. Kovačević, E. Meštrović, and M. Eckert-Maksić, Tetrahedron Lett. 46 (2005) 8733-8736.
10. M. Eckert Maksić, Z. Glasovac, P. Trošelj, A. Kutt, T. Rodima, I. Koppel, and I. A. Koppel, Eur. J. Org. Chem. 30 (2008) 51765184.

11. Z. Glasovac, F. Pavošević, V. Štrukil, M. Eckert-Maksić, M. Schlangen, and R. Kretschmer, Int. J. Mass Spectrom. 354 (2013) 113-122.

12. D. Barić, I. Dragičević, and B. Kovačević, J. Org. Chem. 78 (2013) 4075-4082.

13. Z. Glasovac, M. Eckert-Maksić, Z. B. Maksić, New J. Chem. 33 (2009) 588-597.

14. Gaussian 03, Revision D.02, M. J. Frisch, G. W. Trucks, H. B Schlegel, G. E. Scuseria, M. A. Robb, J. R. Cheeseman, J. A Montgomery, Jr., T. Vreven, K. N. Kudin, J. C. Burant, J. M. Millam, S. S. Iyengar, J. Tomasi, V. Barone, B. Mennucci, M. Cossi, G. Scalmani, N. Rega, G. A. Petersson, H. Nakatsuji, M. Hada, M. Ehara, K. Toyota, R. Fukuda, J. Hasegawa, M. Ishida, T. Nakajima, Y. Honda, O. Kitao, H. Nakai, M. Klene, X. Li, J. E. Knox, H. P. Hratchian, J. B. Cross, V. Bakken, C. Adamo, J. Jaramillo, R. Gomperts, R. E. Stratmann, O. Yazyev, A. J. Austin, R. Cammi, C. Pomelli, J. W. Ochterski, P. Y. Ayala, K. Morokuma, G. A. Voth, P. Salvador, J. J. Dannenberg, V. G. Zakrzewski, S. Dapprich, A. D. Daniels, M. C. Strain, O. Farkas, D. K. Malick, A. D. Rabuck, K. Raghavachari, J. B. Foresman, J. V. Ortiz, Q. Cui, A. G. Baboul, S. Clifford, J. Cioslowski, B. B. Stefanov, G. Liu, A. Liashenko, P. Piskorz, I. Komaromi, R. L. Martin, D. J. Fox, T. Keith, M. A. Al-Laham, C. Y. Peng, A. Nanayakkara, M. Challacombe, P. M. W. Gill, B. Johnson, W. Chen, M. W. Wong, C. Gonzalez, and J. A. Pople, Gaussian, Inc., Wallingford CT, 2004.

15. C. Laurence, J. F. Gal, Lewis Basicity and Affinity Scales, J Willey and Sons Ltd, 2010.

16. (a) S. J. Grabowski (Ed.), Hydrogen Bonding - New Insights. Challenges and Advances, in: Computational Chemistry and Physics, Springer: Dordrecht, The Netherlands, 2006, (b) P. Gilli, V. Bertolasi, V. Ferretti, and G. Gilli, J. Am. Chem. Soc. 116 (1994) 909-915, (c) P. Gilli,V. Bertolasi, V. Ferretti, and G. Gilli, J. Am. Chem. Soc. 122 (2000) 10405-10417, (d) P. Gilli, V. Bertolasi, L. Pretto, L. Antonín, and G. Gilli, J. Am. Chem. Soc. 124 (2002) 13554-13567, (e) P. Gilli, V. Bertolasi, L. Pretto, V. Ferretti, and G. Gilli, J. Am. Chem. Soc. 126 (2004) 3845-3855, (f) P. Gilli and G. Gilli, J. Mol. Struct. 972 (2010) 2-10, (g) S. J. Grabowski, Annu. Rep. Prog. Chem., Sect. C: Phys. Chem. 102 (2006) 131-165. 